\title{
Uma Aplicação Mobile para Mediação de Aulas de Educação Ambiental e Biologia.
}

\author{
Francisco José Carvalho Costa ${ }^{1}$, Matheus William Gomes dos Santos1, Átila R. \\ Lopes $^{1}{ }^{2}$ \\ 1Universidade Estadual Do Piauí (UESPI) - Parnaíba-PI - Brasil \\ 2Instituto de Ciências Matemática e de Computação (ICM/USP) - Universidade de São \\ Paulo \\ Caixa postal13.566-590 - São Carlos- SP-Brasil

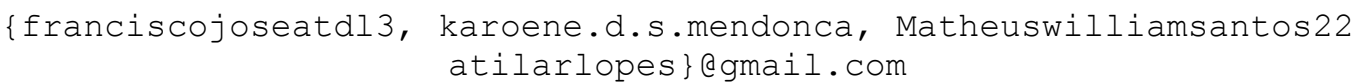

Resumo: Neste trabalho apresentaremos uma proposta de desenvolvimento de uma aplicação móvel para auxiliar em aulas de biologia e conscientização ambiental, mostrando com base em aportes teóricos como a educação baseada em M-learning pode ser positivamente produtiva. A problemática de desenvolvimento partiu da dificuldade em apresentar as atividades de educação ambiental, desenvolvidas no II trail de Barra Grande - Pi, por questões de locomoção do alunado. A aplicação terá seu funcionamento baseado na montagem de uma composteira virtual e espaços de interação com usuário com conteúdos relacionados a botânica. A aplicação proposta terá sua avaliação baseada na experiência do usuário, como uma ferramenta educacional, os resultados finais de cada jogada servirão como base para análise do desempenho dos alunos, a partir de relatórios gerados no próprio jogo.

\begin{abstract}
In this work, we will present a proposal to develop a mobile application to assist in biology and environmental awareness classes, showing, based on theoretical contributions, how education based on M-learning can be positively productive. The issue arose from the difficulty in presenting the environmental education activities, developed in the II trail of Barra Grande $P i$, due to the student's locomotion. The application will have its operation based on the assembly of a virtual composter and spaces of interaction with user that will have contents related to botany. The proposed application will have its evaluation based on the user experience, as an educational tool, the final results of each play will serve as a basis for analyzing the students' performance from reports generated in the game itself.
\end{abstract}

\section{Introdução}

No Brasil, a sociedade informacional moderna, tem sido sinônimo de produção residual excessiva em suas práxis cotidianas. Dados do Instituto Brasileiro de Geografia e Estatística - IBGE, apontam que pelo menos metade das (5.507) cidades do país não planejam o manuseio de detritos residuais, ainda: segundo relatório da Associação de 
Empresas de Limpeza Pública e resíduos especiais - Abrelpe, em 1600 cidades do Brasil existem uma média de 3.000 lixões a céu aberto.

Esses excessos impactam negativamente na qualidade de vida dos indivíduos em contato direto ou indireto com o lixo, o fluxo natural do meio ambiente e das cidades. Alagamentos, doenças virais e contaminação de lençol freático, são alguns exemplos de consequências acarretadas pelo descarte inadequado de lixo1. Neste aspecto, destaca-se o lixo orgânico, caracterizado por sobras alimentícias como legumes, frutas, dentre outros exemplos de materiais orgânicos, e que também impactam no volume de produção residual. Uma pratica para amenizar tal problema é a compostagem.

Em relação ao lixo orgânico, a compostagem é uma técnica de reciclagem simples e eficiente para o tratamento de detritos orgânicos. Um processo biológico de transformação de resíduos orgânicos em substâncias húmicas que consiste no resultado da mistura de matéria orgânica2, dada principalmente por meio de microrganismos, podendo ser dividida em desintegração física e desintegração química. [CT/50, Embrapa Agrobiologia, dez. /2001, p.2]. Tal processo consiste na mistura de matéria orgânica com terra e folhagem em vasilhames com furos na região inferior que servirão para a coleta do chorume, excreção líquida decorrente da síntese da composteira.

No entanto, o ensino prático do processo de compostagem deve ser realizado em locais abertos, com chão de areia, onde os participantes dessa atividade devem levar consigo todo o material necessário para esse tipo de reciclagem. Essas dificuldades podem comprometer a execução desse tipo de atividade e dificultar na aprendizagem mais clara do assunto.

O uso de tecnologias móveis como recurso didático em educação ambiental pode ajudar a minimizar as dificuldades relacionadas às práticas de compostagem, devido às características e os benefícios que a computação móvel pode oferecer para o processo educacional, tais como mobilidade, motivação, interatividade, entre outros. A $M$ Learning (Aprendizagem móvel) é entendida como a aprendizagem utilizando dispositivos característicos da computação móvel (Parsons \& Ryu, 2006), desta forma, o objetivo principal desta produção é apresentar a proposta de uma aplicação móvel, para auxiliar em aulas de biologia e conscientização ambiental, mostrando com base em aportes teóricos como a educação baseada em M-learning pode ser positivamente produtiva.

A educação ambiental conjuntamente à tecnologia, têm sido fortes aliadas na busca por soluções aos problemas suscitados anteriormente. Durante o desenvolvimento desta pesquisa, as tecnologias digitais, serão utilizadas na construção de sentido de uma aprendizagem com foco em estruturas informacionais móveis. Uma vez que o presente trabalho é fruto de uma análise etnográfica a partir da aplicação de um projeto de educação ambiental, desenvolvido pelos alunos do curso de licenciatura em ciências biológicas da Universidade Federal do Piauí, campus Parnaíba no ano de 2018.

Por questões de dificuldade na locomoção intermunicipal, a metodologia de desenvolvimento, as práticas e os resultados do projeto de educação ambiental não puderam ser presentados aos alunos da escola municipal Edson Cunha, uma vez que o

\footnotetext{
${ }^{1}$ Disponivel em: https://g1.globo.com/natureza/noticia/2018/09/14/brasil-tem-quase-3-mil-lxoes-em1600-cidades-diz-relatorio.ghtml

${ }^{2}$ Substâncias de coloração escura, sintetizado por meio da mistura de resíduos orgânicos de plantas, animais e micro-organismos.
} 
mesmo se deu em outra cidade. Neste contexto, a problemática de desenvolvimento desta pesquisa, parte da salientação de como ensinar educação ambiental a alunos de escolas públicas por meio da montagem de composteiras sem sair de suas escolas, com auxílio de tecnologias moveis.

A presente discussão foi baseada em aspectos educacionais levando em consideração características e conceitos de no contexto da conscientização social sobre práticas de manejo de detritos orgânicos. Uma vez que educação, segundo Aurélio (2010) é a "aplicação dos métodos próprios para assegurar a formação e o desenvolvimento físico, intelectual e moral de um ser humano; pedagogia, didática, ensino", tomaremos o meio formacional como ambiente etnográfico, sem desconsiderar que a composição social contemporânea, tem sua aprendizagem fomentada pela extensão que ultrapassa o ambiente escolar [Barbero 2014].

\section{Computação Mobile: implicações na educação e fatores integrantes.}

A existência da sociedade moderna é marcada pelo uso constante de mídias digitais móveis, isto possibilita a imersão em um contexto de aprendizagem contínua, de acesso independente ao conhecimento, "as tecnologias invadem as nossas vidas, ampliam a nossa memória, garantem novas possibilidades” Kenski (2012).

Santaella (2013, p 17) define a computação móvel "pela possibilidade de movimentação física humana levando junto consigo serviços computacionais ”, logo, quebra-se a ideia de limite e o acesso à tecnologia se torna ininterrupto no contexto dos espaços físicos e assim temos uma ressignificação do conceito de "lugar". Mobilidade, em caráter de seu conceito tecnológico, como descrito anteriormente, passa a ser um fator de sentido mediador na efetivação do que se tem em face da educação moderna, notada pela presença enfática do acesso facilitado a informação a qualquer momento e/ou espaço.

Notadamente, temos o enviesar ao conceito de aprendizagem mobile. $\mathrm{O}$ ensino e a aprendizagem tornam-se mais lúdicos e dinâmicos com uso das mídias digitais, e aqui "o professor não é mais aquele que transmite determinado saber pronto. Ser professor na cultura digital implica coordenar, orientar, incentivar a aprendizagem colaborativa cada vez mais personalizada. Não se trata mais de uma tarefa para todos num determinado espaço e tempo. O professor agora é aquele que coordena as atividades em torno de algum problema" Couto (2013 p. 2)

Kambourakis, Kontoni e Sapounas (2004) citam a aprendizagem móvel como "o ponto em que a computação móvel e o e-Learning se cruzam para produzir uma experiência de aprendizagem a qualquer hora e em qualquer lugar". A aprendizagem então se fundamenta na utilização de componentes computacionais móveis, e estes servem como instrumentos mediadores na construção do conhecimento, celulares, tablete e notebook, são alguns exemplos.

A educação abstraiu as múltiplas facetas da evolução social, do caminhar das culturas, e se resinificou junto às tecnologias e da ensino e aprendizagem. A mobilidade expande as possibilidades do acesso ao conhecimento, junto a conexão facilitada com a internet. Jekins (2009) destaca a imersão do indivíduo, ao ser permeado pelas mídias, e elenca ainda as implicações expressivas nas relações sociais, desencadeando novas concepções de educação. E isto não se distância da conscientização sobre aspectos ambientais e conduta social. 


\section{Descrição da Proposta}

Usando dos conceitos de mobilidade, propomos então, o desenvolvimento de uma aplicação mobile, atrelada a algumas práticas de gameficação, para apresentar aos estudantes da rede pública municipal de ensino em Parnaíba-Pi, as etapas e implicações da atividade de montagem de uma composteira, e auxiliar no trabalho dos professores e estagiários no ensino de biologia e educação ambiental no universo da aprendizagem mobile.

A aplicação será desenvolvida no laboratório de tecnologias educacionais, da Universidade Estadual do Piauí - Parnaíba; com base na arquitetura Cliente-Servidor. Na camada servidor, serão dispostas as informações necessárias ao funcionamento da aplicação, tais como: dados sobre o espaço, cadastro de usuários, e manuseio de informações geradas a partir da experiência do usuário, base dedados, relatórios de desempenho e formulários. A interface de interação com o usuário será disposta na camada cliente, ambiente composto pelo conteúdo informacional/instrucional da aplicação.

\section{Caracterização do ambiente M-learning}

Parte de seu funcionamento se baseia em uma interface de interação com o usuário, que apresenta telas de perguntas e respostas e conteúdos instrucionais organizado por etapas onde na fase final do conteúdo, um jogo interativo é caracterizado pela montagem de uma composteira virtual. O material para reciclagem a ser adicionado na composteira ficará a escolha do usuário e neste espaço ficarão dispostos, a exemplo: folhas, garrafas, sobras de legumes, dentre outros compostos, sejam eles orgânicos ou não.

A intenção é fazer com que o usuário, por meio da pratica virtual, entenda o que pode ou não estar presente no processo de reciclagem e conheçam tal processo. Além da montagem do espaço de reciclagem do material orgânico (composteira), será reservado um espaço voltado ao conteúdo de botânica, imagens, textos e perguntas sobre o conteúdo potencializando a conhecimento dos alunos em relação aos espaços naturais e suas características.

O professor poderá analisar o desempenho dos alunos por meio dos relatórios de experiência na aplicação enviados pelos alunos logo após o termino da utilização, ou por meio do quadro de desempenho local de cada aplicativo. Por sua característica móvel, o professor poderá usar o aplicativo para mediar suas aulas dentro e fora das salas ou escola, efetivando mais uma vez a m-learning, a aplicação também servirá como uma referência para montagem de uma composteira física, dando passo a passo da montagem e dicas de produção como disposto na figura 1 abaixo. 


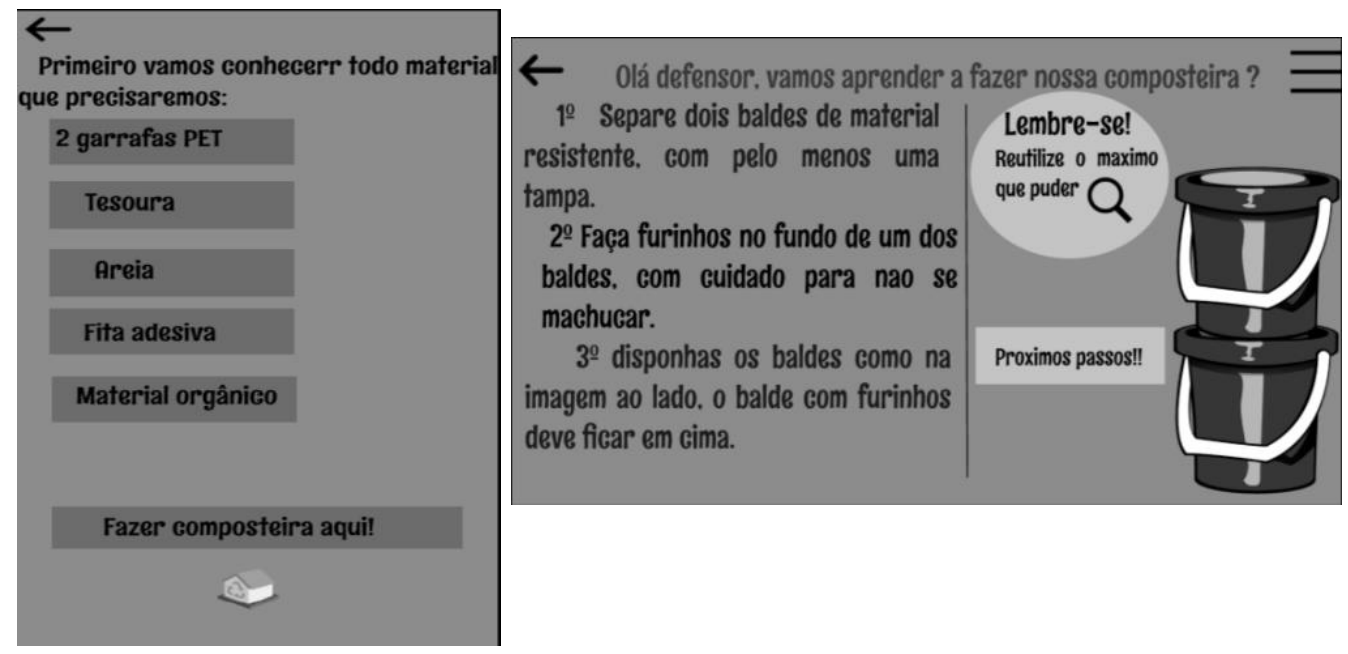

Figura 1.

A lista de materiais na contida na figura 1.0, é parte da instrução para montagem da composteira física, o botão representado pelo ícone de uma "casa" inicia o manual de instruções e o acompanhamento da montagem da composteira física, como mostra a figura 1 .
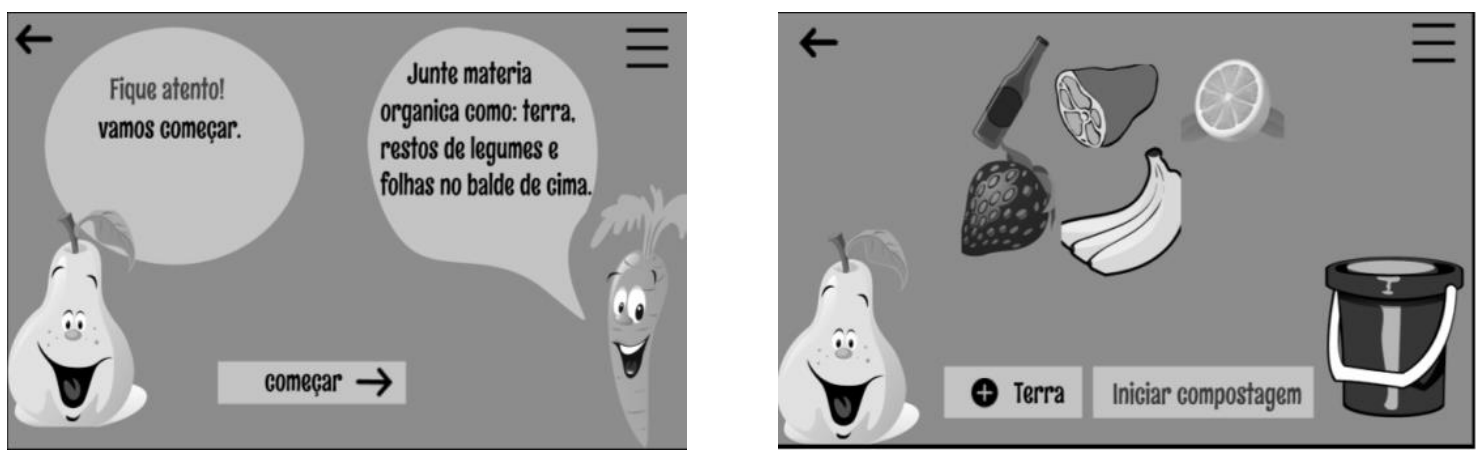

Figura 2.

No botão "fazer composteira aqui", a montagem da composteira virtual será iniciada, e o usuário redirecionado para telas de informações sobre como a prática de montagem virtual acontecerá (figura 2). Na tela de escolha do material a ser adicionado na composteira virtual, diferentes tipos de matéria orgânicas e não orgânicas serão exibidas para que ao fim haja resultado de êxito ou não no processo de maturação, todos os resultados são listados numa projeção cronológica, para formação de um panorama do desempenho do aluno envolvido na atividade.

$\mathrm{Na}$ fase maturação (figura 3), todos os materiais adicionados à composteira serão analisados, se adicionada a matéria orgânica adequada, o processo seguirá até que o composto orgânico esteja pronto, se não, o aluno será aconselhado a escolher novamente os produtos e o processo de maturação será reiniciado, ao final, uma mensagem será exibida com o resultado da sintetização. 


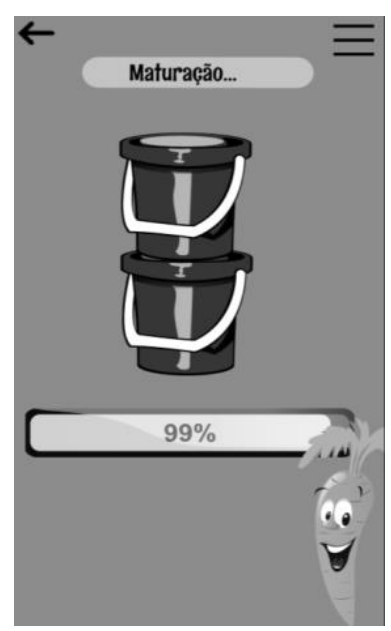

Figura 3.

\section{Discussões}

O enfoque central deste trabalho é mediar a comunicação entre a educação formal descentralizada, conscientização ambiental e aprendizagem mobile com auxílio de tecnologias digitais moveis. "A sociedade e as tecnologias não seguem um rumo determinista. $\mathrm{O}$ rumo depende muito dos seres humanos e, sobretudo, da sua capacidade de discernimento coletivo" Kenski (2012, p. 67) apud Ponte (2014) e as escolas não podem ficar fora da evolução social caracterizada pelo uso de tecnologias digitais.

A proposta de produção da aplicação aqui apresentada, levará ao ambiente educacional as aplicações e possibilidades das tecnologias móveis, configurando-se como ferramenta de extensão dos espaços de conhecimento. "A escola não vai perder sua posição de instituição social e educacional, vai sim, ampliar sua missão" (Azevedo 2014), isso potencializa ao indivíduo presente no ambiente formacional "responder a uma pluralidade de mandatos sociais (de instrução, de socialização, de profissionalização de participação cívica de formação ética, de desenvolvimento estético)" (Azevedo 2014).

A ferramenta dará possibilidades ao entendimento e interpretação da presença do aspecto computacional nas escolas e de como o conhecimento permeia pelas tecnologias móveis, levando em consideração que "o conhecimento é uma mistura fluida de experiência emoldurada, valores, informação contextual e insight" Danvenport e Prusak (1998, apud liaw et al.,2010). Promover o uso da ferramenta aqui proposta, resinificará a dinâmica do ambiente das salas de aula, levando a sociedade informacional, se baseando em processos abertos de educação3.

\section{Considerações Finais e Trabalhos Futuros}

Com base na discussão aqui apresentada, entende-se como relevante o uso de tecnologias móveis para aperfeiçoamento de resultados em ambientes de educação formalizada, expandir os espaços das salas e potencializar o caráter tecnológico e social de objetos de aprendizagem. Como proposta de trabalhos futuros do laboratório de tecnologias educacionais, temos a conclusão do desenvolvimento da ferramenta aqui apresentada, teste e analise de resultados com alunos da rede pública de educação e a implementação de maiores funcionalidades como demonstração, por meio de imagens e vídeos 3D do espaço de projeção do conteúdo trabalhado no aplicativo. As imagens serão visualizadas

3Processos de aprendizagem abertos significam processos espontâneos, assistemáticos e mesmo caóticos, atualizados ao sabor das circunstancias e de curiosidades contingentes. $\mathrm{O}$ advento dos dispositivos moveis ativou esses processos(...) - Santaella, Lucia (2013). 
com um auxílio de óculos VR (Realidade Virtual), proporcionando assim uma experiência de imersão ao espaço mostrado nas imagens, este espaço poderá ser opcional e, o foco inicial é que cada aluno produza seus óculos com ajuda materiais recicláveis como garrafas, papelões com auxílio dos colegas de sala e profissionais presentes.

\section{Referências}

AQUINO, A. M. de; RICCI, M. dos S. F.; FEIDEN, A. Embrapa Agrobiologia, Comunicado técnico -Compostagem; SOUZA, F. A. de;

Kenski, Vani Moreira. Educação e tecnologias: O novo ritmo da informaçã0. $8^{a}$ edição Campinas, SP, 2012.

Santella, Lucia, Aprendizagem ubíqua: repercussões na cultura e na educação. São Paulo: paulus, 2013

Jekins, Henry. Cultura da convergência. Tradução: Susana Alexandria. 2. Ed. São Paulo: Aleph,2009

Martin-Barbero, jesus, A comunicação na educação. Tradução: Maria Immacolata Vassallo de Lopes e Dafne Melo. São Paul: Contexto 2104.

Liaw, shu-sheng; HATALA, Marek, HUANG, Hsi-Mei. "Investigating acceptance towad mobile learnig to assist individual knowledge management: Based on activity theory approach". Computer \& Education 2010.

Couto, Evaldo Souza. Educação 3.0 é a tecnologia que integra pessoas. 26 de março de 2013. Disponível em: http://porvir.org/educacao-3-0-e-tecnologia-integra-pessoas/. Acesso em: 01 de março de 2019.

Conheça algumas tecnologias para tratamento de resíduos sólidos. VGresiduos, 7 de novembro de 2017. Disponível em: https:/www.vgresiduos.com.br/blog/conhecaalgumas-tecnologias-para-tratamento-de-residuos-solidos/. Acesso 25 de fev. 2019.

Brasil tem quase 3 mil lixões em 1.600 cidades, diz relatório disponível, por Elaine Bast, TV Globo. 14 de set. 2018 disponivel em: $<$ https://g1.globo.com/natureza/noticia/2018/09/14/brasil-tem-quase-3-mil-lxoes-em1600-cidades-diz-relatorio.ghtml >. Acesso: 26 de março 2019.

Júlia de Almeida Costa Montesanti. Lixão. Disponível em: https://www.infoescola.com/ecologia/lixao/

STEVERSON, F.J. Humus chemisty: genesis, composition, reactions. 2 ed New York: John Willey, 1994, 496p.

Kambourakis, G., Kontoni, D. P. N., \& Sapounas, I. (2004). Introducing Attribute Certificates to Secure Distributed E-Learning or M-Learning Services. Anais da Conferência Internacional IASTED. Innsbruck, Austrália. p 436-440.

Parsons, D., \& Ryu, H. (2006). A framework for assessing the quality of mobile learning. Massey University website 